\title{
Analysis of the Path of Exhibition Economy Development in the Background of the "One Belt One Road"
}

\author{
Qian Chen ${ }^{1, a}$ \\ ${ }^{1}$ Chongqing College of Finance and Economics, Chongqing, 402160 \\ a email
}

Keywords: One Belt One Road, Exhibition Economic, Development Method

\begin{abstract}
The exhibition industry has become an important way to promote the development of urban economy, improve urban infrastructure and improve the visibility of the city with its strong fire and lead. A good image of the city and a strong industrial base will also promote the development of urban exhibition industry, attract more exhibitors, improves the visibility and influence of the exhibition industry. One Belt One Road "for the exhibition industry spatial distribution and industrial integration provides a historical opportunity, how to clearly locate the cultural exhibition function, the resource advantages into industrial advantages, and strive to build a cultural exhibition industry support platform to promote along the town, industrial chain and urban network communication and development ideas is the key, through a comprehensive background of the development of cultural exhibition industry under the opportunity to conduct a comprehensive analysis, summed up the cultural exhibition industry cultural connotation, explore the impact of cultural exhibition industry and development strategies, with a view to the development of cultural exhibition industry has benefit.
\end{abstract}

\section{Introduction}

"One Belt One Road" is the "Silk Road Economic Zone" and "the 21st century Maritime Silk Road" short, this strategic concept is the first 2013 Xi Jinping President visited the Central Asian countries and Indonesia, respectively, when the proposed cooperation between China and related countries The strategic vision has been written into the "government work report" in 2014, becoming an important national development strategy. On March 28, 2015, the National Development and Reform Commission, the Ministry of Foreign Affairs and the Ministry of Commerce jointly issued the Vision and Action to Promote the Economic Development of the Silk Road and the Maritime Silk Road in the 21st Century (hereinafter referred to as "Vision and Action") The "historical and cultural heritage One Belt One Road," and "jointly organized special investment, trade and cultural exchange activities." Among them, it is of great significance to give full play to the trade fair And the constructive role of cultural exchange has further reflected the necessity and importance of carrying out the development of cultural exhibition industry, setting up cultural exhibition platform and playing the function of cultural exhibition industry market, service, trade and cultural exchange platform. The essence of the "One Belt One Road" strategy is to strengthen the exchange, cooperation and cooperation between countries in the region of "One Belt One Road", and to open up external windows and platforms. This provides a historical opportunity for cultural exhibition industry. At present, the research on the development strategy and path of cultural exhibition industry under the background of "one side by one" at home and abroad is based on the analysis of the connotation of the whole economic belt and the realization of the path, or focus on the future development plan of a certain region, and pay little attention to the cultural industry and exhibition industry The combination of cultural exhibition industry in the "one side" under the background will play a cluster effect and platform role in the cultural exhibition industry in the "One Belt One Road" under the background of the cluster effect and the role of the platform in-depth study will provide a basis for national strategy, For the relevant regions and departments involved in the economic zone construction of the role of cultural exhibition industry awareness and 
strategic positioning to provide intellectual support.

\section{"One Belt One Road" Cultural Connotation}

From the perspective of domestic and foreign perspectives, "One Belt One Road One Belt One Road" for the common development with other countries, cultural communication, further opening up, balance the development of the central and western regions, to maintain national security is of great significance. Shi Guangsheng at the Sixth China (Chengdu) Convention and Exhibition Economic Conference put forward the industry on the exhibition functions are located in the dissemination of new technologies, trade and marketing functions, "and its promotion of productivity and the progress of human civilization and the role of the economy and the economy Political strategy connotation is rarely mentioned. " Zhou Junsheng, An Yuhong, etc. (2015) that "'all the way' highlights China's new economic development ideas will help solve the problem of insufficient domestic demand and excess capacity to further promote access, navigation, trade, is conducive to mutually beneficial resource allocation And promote international trade liberalization and globalization, it provides an important investment direction, a new round of reform and opening up the strategic focus, but also China's major policy dividend for the next decade. "Yuan Xintao (2014) from the important significance of historical opportunities , Faced with challenges and the realization of the path of multi-angle analysis of the strategy, he believes that One Belt One Road with the promotion of intercountry culture, economic and trade further exchanges and communication, has a good basis for international cooperation, but also faces foreign interference and domestic possible disorder competition.

Experts at home and abroad stressed the need to consolidate the basis of cooperation, culture first drive economic cooperation, promote the Silk Road between the revival of cooperation between countries. Yuan Xintao (2014) believes that the first foreign countries to strengthen cooperation with the Central Asian countries such as the Russian Federation of Russia and other countries, the country to further promote the all-round open pattern, Zhang Yunling (2014) that the surrounding areas of strong desire to develop, should build a strategic chain. Tourism can be used as a "lead One Belt One Road" the construction of the pilot industry, tourism cooperation in order to strengthen communication at the same time bring people flow, logistics, information flow and capital flow, even that should promote cultural and tourism depth integration, the construction of Silk Road cultural economic zone, Cultivate regional cultural industry cluster, the construction of Silk Road cultural industry belt, expand channels to build cultural exchange and cooperation platform, build a number of demonstration cultural industry projects, deepen the cultural system reform.

\section{The Influence of Cultural Exhibition Industry under "One Belt One Road"}

Nie Jian, Xiao Lu (2012) that the exhibition industry is a modern service industry and cultural and creative industries, covering a number of industrial chain, is an important engine of local economic development, but also the cultural industry accelerator, Chen Hongjin (2008) (2010) analyzed the relationship between the Expo and the cultural industry and the development of cultural exhibition industry strategy, he believes that "the exhibition industry has its own characteristics of the industry, the Expo will be the development of cultural industries, both to the development of cultural and exhibition industry, Promote the development of cultural industries, but also in line with the characteristics of the exhibition industry and the development trend "; Yin Wen analysis of cultural exhibitions to the creative category, design and digital exhibitions development; Tang Yu Han (2010) and others from a perspective of cultural exhibition Development strategy. He and Qi Yongfeng have proposed in the early stage of the development of cultural exhibition industry, the Fair should be the government-led view, do the overall planning, ICIF strategic positioning is the cultural industry development platform and engine, improve the mode of operation, give full play to cultural exhibition Economic and social benefits.

(2012) proposed that the cultural and social functions of culture were reflected in the value of exhibits, the display value of exhibition hall and the value of exhibition form. Lin Yonglian, Guo 
Lifeng, Zhao Liyun et al. (2012) analyzed the development of cultural exhibition industry in different provinces, (2012) that the integration into the national spirit of the exhibition can not only highlight the national culture, showing the diversity of national culture, but also enrich the connotation of the exhibition; Tang Yu-han (2012) put forward the application and manifestation of regional culture in the exhibition design; Zhang Jun (2014) and Jiang Zhiying respectively analyze the problems of cultural exhibition development from the perspective of a certain exhibition. It is suggested that cultural exhibitions should adhere to internationalization, subjectivity, trade and service from platform to brand, and highlight cultural connotation.

\section{Analysis of the Choice of Cultural Exhibition Industry under the Background of "One Belt One Road"}

First, it is as soon as possible to study the development of cultural exhibition industry development plan. "With all the way" strategy, the western provinces and regions to seize the cultural exhibition industry to promote regional opening of the commanding heights, have put forward the corresponding development strategies and programs, Shaanxi has formed a three key exhibition as the core, with four potential exhibition Gansu, promulgated the "Silk Road Economic Zone," the overall construction of the Gansu section of the program, "proposed to build an international cultural festivals, cultural exhibition to promote the opening of Gansu; Guangxi planned the development of the cultural development of the exhibition, A number of cultural thematic exhibitions, "to promote the Silk Road Economic Zone and the 21st century Maritime Silk Road vision and action" in particular proposed to do the Sichuan West Fair, make full use of the West will serve the "One Belt One Road" Function and advantages, to play the role of West Bohui trade cooperation platform, investment promotion platform and diplomatic service platform, the government should develop cultural exhibition industry development plan as soon as possible to further strengthen the development of cultural exhibition industry, macroeconomic regulation and control, the overall development of cultural exhibition industry Layout, industrial structure, support policies and industry standards Research, development scientific guidance exhibition industry.

Second, strengthen the construction of cultural exhibition industry chain. First of all, it is necessary to form a special exhibition organization and organization of the exhibition industry, but also as soon as possible to develop and introduce the relevant management practices, norms and implementation of the exhibition industry-related laws to strengthen the supervision and management of the exhibition market and create a good exhibition industry development Environment; Second, focus on training to support a strong market competitiveness or development potential of the cultural exhibition backbone enterprises to exhibition enterprises as a leader, the development of transportation, logistics, communications, catering, tourism, accommodation support, planning, advertising, design , Installation, on-site service and other supporting industrial clusters, the formation of industry support, industry linkage of the exhibition industry service system to enhance the industrial chain upstream and downstream enterprises synergies, promote the development of related exhibition services business; again, give full play to the exhibition industry and other industry organizations active Role, give full play to the integration of industry organizations will promote the optimization of exhibition resources to comprehensively enhance the competitiveness of the exhibition industry, extending the exhibition industry chain; Finally, to speed up the training of cultural exhibition related personnel, exhibition industry is operational and strong correlation industry, culture Exhibition personnel training is the cultural exhibition industry Speed development of the necessary requirement.

Third, increase financial support to boost the development of cultural exhibition industry. Culture is the soul of the exhibition, the exhibition industry as a result of product display and marketing, brand promotion, information dissemination, industry linkage, promote employment, promote urban construction and other platform functions, which itself is high income, high profit industry, profit margins in $25 \%$, there is a strong economic linkage and promote the characteristics of industrial upgrading, destined to its "One Belt One Road" strategy to play an indispensable role in the implementation. And as a cultural industry categories of cultural exhibition industry not only 
has the basic functions of the exhibition industry, as well as active cultural market, set up cultural industry display, trading and financing platform to optimize the cultural industry structure and so on, in the "One Belt One Road" background development potential , To increase financial support to boost the development of cultural exhibition industry is important and urgent, should be the government, business investment, to encourage private institutions and individuals to actively participate in the capital, the formation of multi-channel, multi-level linkage mechanism to support the cultivation of brand exhibition , The new exhibition, cultural exhibition innovation, the introduction of international and domestic large-scale exhibition, etc., to broaden the financing channels of cultural exhibition enterprises, the implementation of the exhibition market, innovation exhibition brand encouragement policies to support local governments, relevant departments, industry associations to develop the existing More influential comprehensive cultural exhibitions, innovative cultural exhibitions to do the form, pay attention to cultural exhibition professional, fully release the cultural exhibition industry spillover effect.

\section{Conclusion}

Cultural exhibitions are a variety of cultural and regional cultural activities, not only in the cultural exchange has important value, but also will produce spillover effects and economic multiplier effect, it through the transaction, exhibition, forum, festival and activities and other forms, To create a display, trade and information platform, both to promote brand marketing products, but also the integration of cultural resources, promote exchanges and cooperation. In recent years, many domestic cultural exhibition activities, but the cultural exhibition activities from the organizational level and brand effect are still to be improved, to comprehensively enhance the level of cultural exhibition industry development, scientific identification of key cultural exhibition positioning, to play their own advantages, resource advantages And industrial advantages, and actively develop the industry and regional characteristics of various cultural exhibitions, to encourage the industry characteristics of distinctive, significant regional characteristics of the focus of the exhibition development, around the festival held a series of theme exhibition activities, and gradually formed a meeting, exhibition, festivals, events , Performances and other activities as one of the "show" pattern.

\section{References}

[1] Zou Jialing, Jiu Chunla, Yin Guoqing. Chinese trade pattern and its economic contribution along with "one side One Belt One Road" [J]. Advances in Geography Science, 2015 (05)

[2] Shou Yijun. "One Belt One Road all the way" against the exhibition industry "new normal" change path [J]. Enterprise technology development, 2015 (14)

[3] Li Yanfang, Li Bo. Development of Bangladesh-China-India-Myanmar Economic and Trade Relations from the Perspective of Sub-regional Cooperation [J]. South Asia Research, 2015 (01)

[4] Liu Haiquan. Security Challenges of "One Belt One Road" Strategy and China's Choice [J]. The Pacific Journal, 2015 (02)

[5] Zhang Jun. Southwest China in the "One Belt One Road all the way" open strategy in the advantages and positioning [J].Economic aspect, 2014 (11) 